\title{
Chaînes opératoires and resource-exploitation strategies in chimpanzee (Pan troglodytes) nut cracking
}

\author{
Susana Carvalho ${ }^{a, *}$, Eugénia Cunha ${ }^{a}$, Cláudia Sousa $^{\mathrm{b}}$, Tetsuro Matsuzawa $^{\mathrm{c}}$

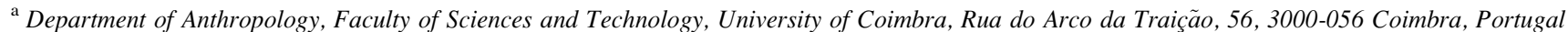 \\ ${ }^{\mathrm{b}}$ Department of Anthropology, Faculty of Social and Human Sciences, New University of Lisbon, Av. Berna, 26-C 1069-061 Lisboa, Portugal \\ ${ }^{\mathrm{c}}$ Primate Research Institute, Kyoto University, 41 Inuyama, Aichi 484-8506, Japan
}

Received 24 May 2007; accepted 4 February 2008

\begin{abstract}
We apply archaeological methods to extend our knowledge of chimpanzee material culture. The chaîne opératoire conceptual framework, as introduced by ethnography, established technology as a phased process. Prehistoric archaeology adopted this concept to elucidate technological variability in tool-making procedures, based on knowledge of tool functions or subsistence patterns. We focused on the detection of operational sequences by wild chimpanzees (Pan troglodytes verus) when nut cracking with lithic implements at the sites of Bossou and Diecké, Guinea, West Africa. Thus, while it has recently been claimed that chimpanzees leave behind recognizable assemblages of stone hammers that can be morphologically distinguished from Oldowan hammers, this is the first study to focus specifically on the existence of operational sequences during the utilization of stone tools by wild chimpanzees. By combining primatological and archaeological methods and examining ecological areas inhabited by different chimpanzee groups, we sought technological variability and identified variables influencing regional diversity in tool typology and technology. We compared three case studies: (1) Bossou-direct recording of experimental nut-cracking sessions; (2) Bossoudirect and indirect monitoring of nut-cracking sites in the wild; (3) Diecké-indirect monitoring of nut-cracking sites in the wild. Results suggest that chimpanzees perform sequences of repeated tool transport and nut cracking. Data show discrimination of tool functions based on tool features. We identified the most technologically complex tool for nut cracking, which was composed of four stones. We found regional diversity in chimpanzee stone assemblages. Raw-material type and tool mobility constrain technological development in human and nonhuman primates. Spatial analysis of tool distribution indicates a pattern of resource-exploitation strategy, revealing affinities with Oldowan.
\end{abstract}

(C) 2008 Elsevier Ltd. All rights reserved.

Keywords: Chimpanzee archaeology; Technology; Tool use; Tool making

\section{Introduction}

Chaîne opératoire theory was introduced by ethnographers as a way to describe traditional techniques (Mauss, 1967). Applications of the concept to archaeology date to research in the 1970s on the Upper Paleolithic site of Pincevent (Leroi-Gourhan and Brézillon, 1972). It gave to prehistoric

\footnotetext{
* Corresponding author. Present address: Leverhulme Centre for Human Evolutionary Studies, Department of Biological Anthropology, University of Cambridge, Fitzwilliam Stree, Cambridge CB2 1QH, UK. Tel.: +44 (0) 1223764720; fax: + 44 (0) 1223764710 .

E-mail address: scr50@cam.ac.uk (S. Carvalho).
}

archaeology a way to identify different phases of blank production in tool making and use in a lithic assemblage (Sellet, 1993; Lucas, 2000). Lemonnier and Leroi-Gourhan reoriented the archaeological focus, thus producing a dynamic interaction between the object and the technological activity process (Leroi-Gourhan, 1964; Lemonnier, 1983; Pelegrin et al., 1988; Karlin et al., 1991; Sellet, 1993). The main stages of the chaîne opératoire, as applied in lithic studies, are: rawmaterial selection, blank production, tool production, tool use, recycling or maintenance, and discard (Almeida, 2000). Differing strategies can tell us about variability and can explain cultural variation between related or neighboring groups of populations (Bar-Yosef et al., 1992; Perlès, 1992). 
Before this conceptual framework emerged, the study of archaeological remains focused mainly on typological analysis of end products (Bordes, 1961). Later, archaeologists sought to comprehend the whole technological procedure and toolmaking variability based on knowledge of function or subsistence patterns (Binford, 1980; Boëda et al., 1990). Knowing the operational sequence of tool making allows the re-creation of the technical history of the object, permitting a concrete understanding of cultural diversity in a community (Tixier et al., 1980).

Use-wear analysis has contributed greatly to operationalsequence studies, giving a more precise assessment of the function of an artifact during its lifetime, as well as the degree of its wear or use (Semenov, 1981; Jardón Giner, 1990; d'Errico et al., 2001; Backwell and d'Errico, 2001). Recent studies supported by use-wear analysis suggest that some early hominin activities were similar to the activities that we can now observe in groups of modern chimpanzees, such as nut cracking (Goren-Inbar et al., 2002). Mercader et al. (2002) argued that chimpanzees' tools may resemble Oldowan tools. However, the apes" stone "hammers" can be morphologically distinguished from Oldowan "hammers." Some of these chimpanzee assemblages from Taï date back 4,300 years, making this behavior contemporary with human activities during the Later Stone Age in this part of Africa (Mercader et al., 2007).

Chimpanzee communities have diverse cultural traditions, which are passed on from one generation to another through social learning (Nishida, 1987; McGrew, 1992; Matsuzawa, 1994; Boesch, 1996; Whiten et al., 1999; Matsuzawa et al., 2001; Whiten and Boesch, 2001; Biro et al., 2003; McGrew, 2004; Biro et al., 2006; Whiten et al., 2007). Bossou and the neighboring communities exemplify a "cultural area," given the chimpanzees' use of stone tools for nut cracking. Nut cracking is found in various populations of chimpanzees in western Africa (Ivory Coast: Beatty, 1951; Boesch and Boesch, 1982; Guinea: Sugiyama and Koman, 1979; Sugiyama, 1981; Kortlandt, 1986; Liberia: Anderson et al., 1983; Hannah and McGrew, 1987; Sierra Leone: Whitesides, 1985; Cameroon: Morgan and Abwe, 2006), while it is absent in central and eastern Africa. The type of nut cracked in each community seems to be mainly determined by cultural traditions: regional differences in tool-use techniques and modes that cannot be explained on ecological or genetic grounds and that are part of the behavioral repertoire of a community, transmitted in a generational form through social mechanisms (McGrew, 1992; Matsuzawa et al., 2001; Biro et al., 2003; Humle and Matsuzawa, 2004; McGrew, 2004).

Bossou chimpanzees have a large repertoire of tool use, including stones used to crack open oil-palm nuts, Elaeis guineensis (Sugiyama and Koman, 1979; Sugiyama, 1981, 1994, 1997; Matsuzawa and Yamakoshi, 1996; Inoue-Nakamura and Matsuzawa, 1997; Whiten et al., 1999; Ohashi, 2006). This behavior has been studied in the forest and, more intensively, in an outdoor laboratory in the core range area of this group (Fushimi et al., 1991; Matsuzawa, 1994, 1996, 1999; Matsuzawa et al., 2001; Biro et al., 2003, 2006). The outdoor laboratory (i.e., a natural area in Bossou
Forest, cleared from vegetation, where raw materials are presented to the chimpanzees during controlled sessions) has provided researchers at Bossou with a unique opportunity to collect systematic and longitudinal data on individual tooluse behaviors, permitting the monitoring of developmental phases involved in the individual acquisition of skills (Biro et al., 2006). At other sites, researchers have also performed systematic studies of nut cracking including, for example, the spatial analysis of tool sites and tool transports carried out successfully by Boesch and Boesch (1984) - but without the equivalent of an outdoor laboratory, direct, close-range, long-term observations have arguably been less feasible than at Bossou.

Few studies of tool use in nonhuman primates have focused on processes of production or technological patterns. Standardized object manipulation can be identified in some ape populations (Byrne and Byrne, 1993) and the necessary cognitive complexity can be compared with rudimentary human craft technology (Byrne, 2007). The tool-using techniques that chimpanzees developed can be seen as a form of problem solving (Stokes and Byrne, 2001), but the degree of technical complexity and variability may be affected by environmental and social factors that demand an adaptive solution (Byrne, 1996). By detecting different patterns of tool use in diverse groups of the same species (Pan troglodytes), we can provide new insights into their strategic choices that may be indicators of real intelligence (Byrne, 1995). Knowledge of operational sequences of tool use can serve as a guide to underlying mental organization and anticipation of tasks (Stokes and Byrne, 2001).

Archaeological concepts and methods can extend our knowledge of chimpanzee material culture (Wynn and McGrew, 1989; Sept, 1992; Toth and Schick, 1993; Joulian, 1996; Schick et al., 1999; Mercader et al., 2002; Goren-Inbar et al., 2002; Davidson and McGrew, 2005; Heaton and Pickering, 2006; Mercader et al., 2007). The case for developing an interdisciplinary approach between primatology and archaeology is compelling (McGrew, 2004); it provides archaeology with the foundations to start modeling the evolutionary origins of technology (Marchant and McGrew, 2005). For early hominins, a diversity and multiregional focus on cultural emergence may be detectable (Davidson and McGrew, 2005); that is, the first lithic industries were probably not a monopoly of any single hominin species (Semaw et al., 1997; Semaw et al., 2003). In primatology, research systematically centers on the use of tools, as reflected in the constant use of the term "tool use" in the literature. The tool was initially thought to be a physical extension of the primate (Goodall, 1964). Later, more inclusive definitions (e.g., Matsuzawa, 1999) categorized various types of tool use, thus attributing to them connotations that are more complex. However, even today, researchers rarely separate the tool from its user, considering it an individual entity with its own technological history, reflecting a set of social and economic conditions of a specific group.

The study that is the subject of this report focused on an operational sequence used by wild chimpanzees (Pan troglodytes verus) in nut cracking with lithic tools in the areas of 
Bossou and Diecké (Guinea). The study was conducted in three phases:

(1) Direct recording during experimental nut-cracking sessions in Bossou. Regarding individual behavior and tool technology, the goal was to identify and analyze each phase of an operational sequence. Concerning individual analysis, the objective was to detect tool features that serve as indicators of chimpanzee stone-tool typology and technology.

(2) Direct and indirect recording through monitoring of natural nut-cracking sites in Bossou. The aim was to test, directly and indirectly, the existence of an operational sequence during nut cracking, in a natural context, comparing the results with the previous phase. Again, tool characteristics were analyzed using typological and technological criteria.

(3) Indirect recording and monitoring of natural nut-cracking sites in Diecké Forest. The goals were to indirectly seek an operational sequence and compare it with the previous phases of typology and technology, given a diverse region with several chimpanzee groups and nut species available.

\section{Study sites and populations: Bossou and Diecké}

Data were collected from January 2006 to May 2006. Two areas were surveyed: Bossou Forest, Sector A (SA), and Diecké Forest, Sector B (SB) (Fig. 1). Bossou is part of the West African craton with Precambrian rocks, which are essentially igneous and metamorphic (Clark, 1967). Movable stones in this area are abundant. Chimpanzees also use stones from the piles built by local villagers (Sakura and Matsuzawa, 1991). Elaeis guineensis nuts are the only species available.

Bossou-Nimba $\left(07^{\circ} 39^{\prime} \mathrm{N} ; 008^{\circ} 30^{\prime} \mathrm{W}\right)$ is one of a small number of long-term field sites for the study of wild chimpanzees in Africa. It is located in southeastern Guinea, $6 \mathrm{~km}$ from the Nimba Mountains. Surrounded by small hills of primary and secondary forest and bordered by savannah in all directions, the area contains a $5-6 \mathrm{~km}^{2}$ home range of daily foraging for this chimpanzee community (Sugiyama, 1981). At the summit of Mount Gban, which chimpanzees cross on a daily basis, stones and nuts were provided in a cleared rectangular outdoor laboratory area measuring $7 \times 20 \mathrm{~m}$ (Matsuzawa et al., 2001; Biro et al., 2003). These conditions permit researchers to watch chimpanzees in their natural habitat without being seen and create the opportunity to study the group's behavior in cross-sectional and longitudinal ways. Over the past 19 years, experiments have been conducted each year in the dry season (December-February), yielding over 20-30 hours of observation per year (Matsuzawa et al., 2001; Biro et al., 2003).

Diecké Forest is part of the Guinean Forests, a component of the lowland forests of western Africa, that survived the retraction and division of Pleistocene forests (Caldecott and Kapos, 2005). Diecké is a protected area of $600 \mathrm{~km}^{2}$ in southeastern Guinea, $50 \mathrm{~km}$ west of Bossou, bordering Liberia on the south. It has many small hills, averaging $350 \mathrm{~m}$ in altitude, and three main rivers cross the forest.

Diecké is also part of the West African craton with Precambrian rocks (Clark, 1967). Enormous granitic outcrops occur in the primary forest, and portable quartz or quartzite stones are found in or near watercourses. Panda oleosa and Coula edulis are the nut species in the core of the forest. Elaeis guineensis is absent, although this species exists in peripheral areas. Local people around Diecké Forest, as in Bossou, crack open oil-palm nuts using stone tools.

Research in Diecké Forest began with preliminary surveys (Matsuzawa et al., 1999; Humle and Matsuzawa, 2001). Diecké chimpanzees were found to crack open Panda oleosa and Coula edulis nuts using stone and root anvils and stone hammers, although nut-cracking activity had to be inferred from trace evidence only. Only a few direct sightings of chimpanzees exist in this area (Kormos et al., 2003).

\section{Subjects: Bossou and Diecké}

For 30 years the Bossou chimpanzees have numbered about 20 individuals (Biro et al., 2003), but group size has dropped in recent years. In 2006, the group had only five males and seven females, including one infant, three juveniles (under 10 years of age), and eight adults.

Chimpanzee feeding, sleeping, and travel traces were found in the core and periphery areas of Diecké forest; the latter provided banana plantations and other agricultural fields as alternative food resources. Surveys are needed to determine the size and the home range of the possible different groups.

\section{Phase 1: Bossou outdoor laboratory (SA1)}

\section{Apparatus and methods}

Twenty-nine experimental sessions were conducted, totaling almost 18 hours. Each experiment started when the first individual entered the outdoor laboratory and finished three minutes after the last individual left the site. Piles of Elaeis guineensis (Eg) and Coula edulis (Ce) nuts were provided in seven locations, and 57 stones were divided into subsets to create two areas of available raw materials (Fig. 2). This set of stones had been used since 1988 by researchers here (Matsuzawa, 1994); thus, it is an artificial assemblage. The placement of stones and nuts was standardized and maintained. Each stone was labeled in paint with a number (1 to 57), measured (length, width, height, weight), and classed as a raw-material type.

The site's datum point $(691.11 \mathrm{~m})$ was set in a wellpositioned tree and secondary reference points were fixed on several trees using GPS (Garmin Map 60 CS). For the horizontal spatial control, the site was hand-drawn with all the stones in their original position (Fig. 2). Changes to the site were kept to the minimum needed to maintain the recording apparatus while being unobtrusive. After fieldwork, drawings were converted to digital format and grids were overlain as 


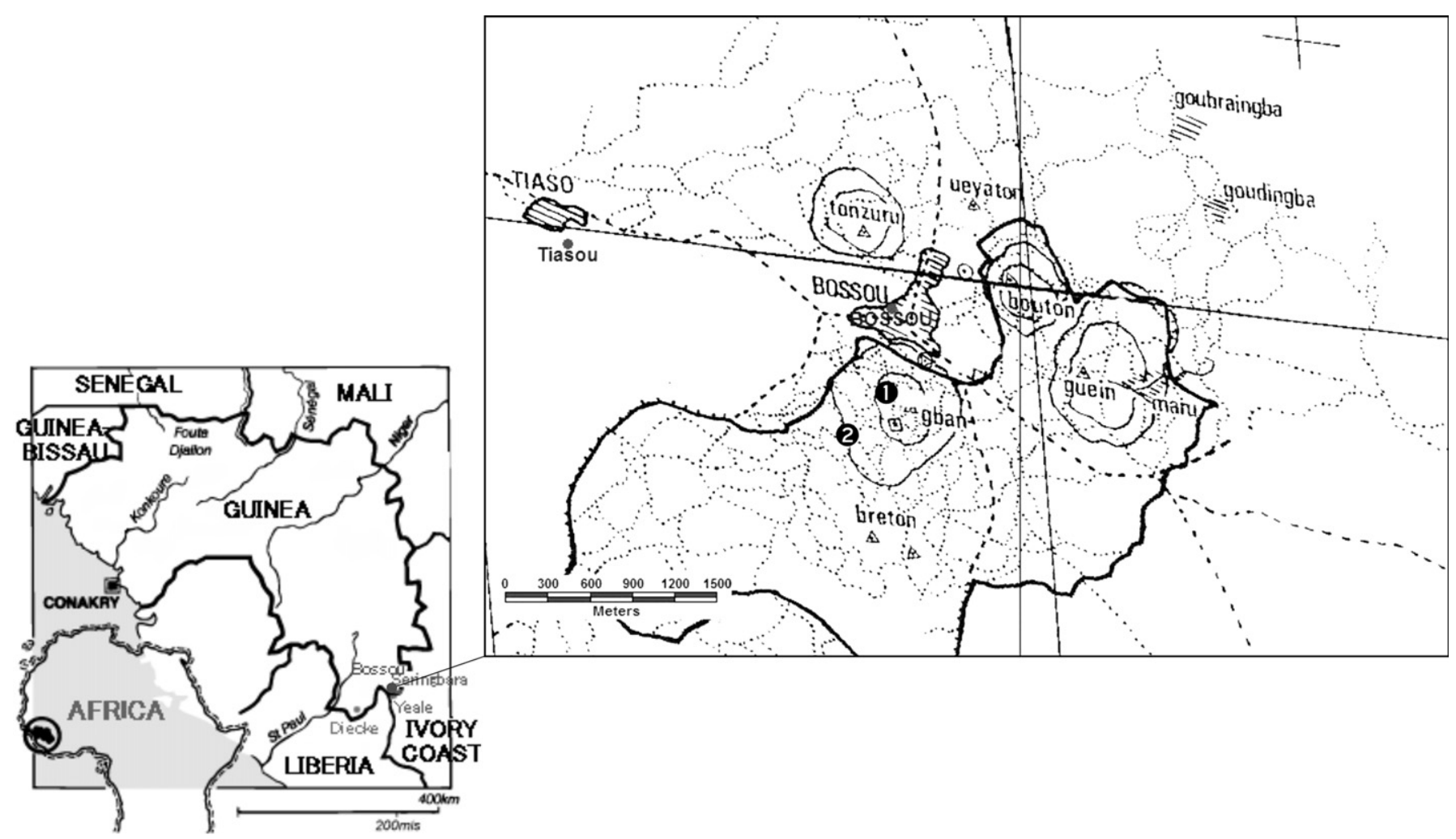

Fig. 1. Left: location of Bossou and Diecké in Guinea, Africa; right: location of the outdoor laboratory (1) and Moblim SA13 site (2) in Bossou area (credits: KUPRI-Japan).

$1 \times 1 \mathrm{~m}$ units, oriented to north. To record the movements of the tools, an efficient and fast method with a minimum of equipment was needed in order for observers to be ready to leave the site as soon as a chimpanzee appeared. The topographic-triangulation method was applied: the vector that establishes tool position was obtained by measuring the distance from the tool to the datum point. Vector direction was determined using the angle between the line defined by the datum point, the tool point, and the meridian direction (north-south). Thus, triangulation was based on two fixed points: magnetic north and the datum point. A string level, a plumb bob, measuring tapes, and a compass (Suunto MC-2, with clinometers) were used to execute the method.

We replaced all of the stones in exactly the same position before each visit by the apes. The activities of the chimpanzees were filmed by either two or three video cameras (Sony Digital Handicam, DCR-VX 1000; Sony Digital Handicam, DCR-PC 110) for later analysis of the fine details of tool use. Tool movements were drawn after each experimental session. Chimpanzees twice interrupted tool recording; these sessions were recorded and combined with the next session.

Nut cracking was recorded in terms of the phases of the potential operational sequence (Table 1). Each time an individual performed an act $(n=1165)$, these and the associated tool numbers were recorded. Tool analysis included tool dimensions and the approximate shape of the tool, using a simplified glossary of stone-tool types from Olduvai Gorge (Leakey,
1971). These were combined with interpretations of Oldowan ad hoc technology (Toth, 1985; Wynn and McGrew, 1989): refitting trials, recent block fractures, flake (or chip) extractions, and tool mobility (Table 2). All drawings from all sessions were analyzed to examine the spatial distribution of tools in the activity area (Fig. 3). Hand drawings (scale $1: 20 \mathrm{~cm}$ ) were transferred to digital drawing (AutoCad software), and GPS coordinates (WGS 84) were introduced into a GIS database (GeoMedia software); video recording (Sony Digital Handicam, DCR-VX 1000; Sony Digital Handicam, DCR-PC 110) was used.

Due to the diverse nature of the collected data, it was necessary to use both parametric and nonparametric tests for statistical analysis. Categorical data, such as available raw materials and tool shape, were analyzed using nonparametric tests. Comparisons between frequencies of categorical variables were made using chi-square test for independent samples. The rationale that underlies chi-square is based on the differences between the observed and the expected frequencies. The observed frequencies were the data produced by the survey, while the expected frequencies were computed on the assumption that no difference existed between the groups except those resulting from chance occurrences. Continuous data, such as width, weight, length, and height, due to their numerical nature, were analyzed using parametric tests. Comparisons between measures of continuous variables were made using the $t$-test for dependent samples since a set of measures were obtained on the same tools. 


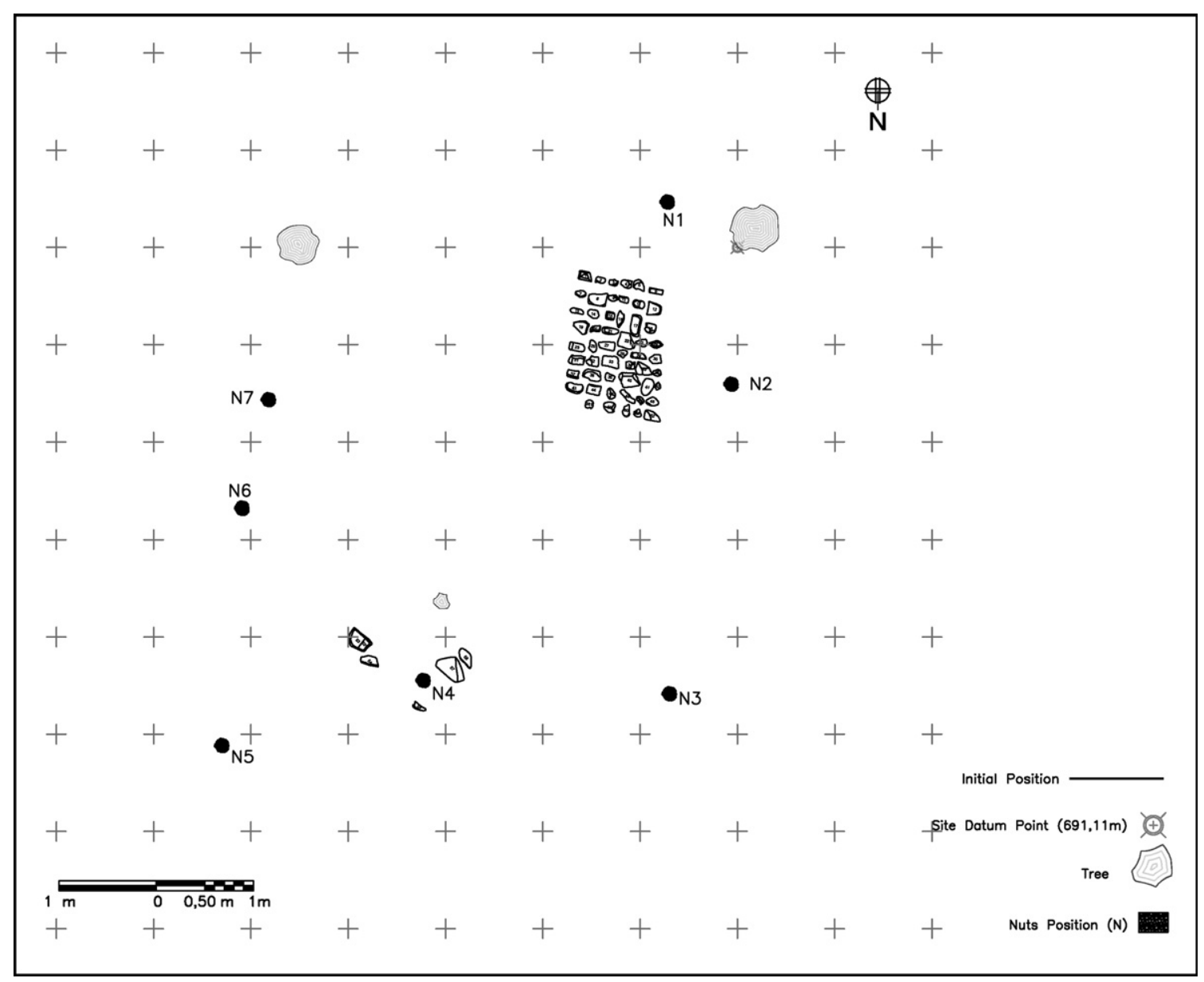

Fig. 2. Experimental tools in their original position at the outdoor laboratory, Bossou.

\section{Results}

Granite, quartz, diorite, dolerite, and conglomerate were the available raw materials, and all tools were movable. There was a significant difference between the most commonly available raw material (granite) and the most-used raw material (diorite): diorite was used more often than expected based on availability $\left(\chi^{2}=4.741 ; p=0.029\right)$.

Of the 57 stones, $33(58 \%)$ were used by the chimpanzees. Of these 33 , nine (27\%) were used both as hammer and anvil. We sought to verify if the other $24(73 \%)$ objects were chosen as either hammer or anvil in accordance with their morphological features. Comparing mean dimensions (width, length, height, and weight) of hammers and anvils, hammers were significantly wider $(t=2.20 ; p=0.038)$ and lighter $(t=-2.345 ; p=0.028)$ than anvils. Hammers and anvils did not differ in height $(t=-1.82 ; p=0.082)$ or length $(t=1.610 ; p=0.112)$. Pearson correlation (twotailed) indicates a significant correlation between tool dimensions and function (Table 3). Hammer and anvil dimensions $(n=57)$ at the outdoor laboratory site were also compared with the results $(n=67)$ of Sakura and Matsuzawa (1991) in the Bossou area, yielding no significant differences between sites (Table 6).
Frequencies of operational-sequence elements were recorded as follows: stone selection for tool construction $(n=$ $324)$, transport $(n=194)$, utilization $(n=382)$, reuse $(n=110)$, change of tool type $(n=135)$, fracture tool $(n=2)$, reuse of fractured tool $(n=9)$, flake extraction $(n=$ $2)$, play with tool $(n=7)$, and discard $(n=10)$. The first three elements showed high frequencies $\left(\chi^{2}=1299.37 ; \mathrm{df}=9\right.$, $p<0.01)$. Differences emerged at the levels of individual, sex, and age. Yolo (YL, dominant male) and Jeje (JJ, juvenile male) selected tools more often than did the rest of the group $\left(\chi^{2}=120.26, \mathrm{df}=10, p<0.01\right)$. Males selected tools more than females $\left(\chi^{2}=32.111, \mathrm{df}=1, p<0.01\right)$. Adults performed more stone selection for tool construction than did juveniles $\left(\chi^{2}=10.383\right.$, df $\left.=1, p=0.001\right)$. Differences were identified in transport behavior, with Yolo and Jire (JR, adult female) exhibiting more tool transport $\left(\chi^{2}=97.65, \mathrm{df}=10, p<0.01\right)$. Males transported the tools more often than females $\left(\chi^{2}=10.91, \mathrm{df}=1, p=0.001\right)$, and adults transported them more than juveniles $\left(\chi^{2}=64.66\right.$, $\mathrm{df}=1, p<0.01)$. Hammers were transported more than anvils $\left(\chi^{2}=99.97, \mathrm{df}=1, p<0.01\right)$. The stone tool transported most often ( $n=22$ times) was a hammer weighing $835 \mathrm{~g}$. One of the most transported tools was also the heaviest stone, weighing $6000 \mathrm{~g}$. 
Table 1

Phases of the potential operational sequence

\begin{tabular}{|c|c|}
\hline Behavior & Description \\
\hline Raw-material selection & Selection of raw-material type \\
\hline $\begin{array}{l}\text { Stone selection for tool } \\
\text { construction }\end{array}$ & $\begin{array}{l}\text { Choosing a tool set to construct a nutcracker } \\
\text { and using each tool during the session for } \\
\text { the same function }\end{array}$ \\
\hline Tool-function selection & $\begin{array}{l}\text { Using a tool as a hammer, anvil, } \\
\text { wedge, or other }\end{array}$ \\
\hline Transport & $\begin{array}{l}\text { Moving a tool from the original position } \\
\text { (Position 1) during a session }\end{array}$ \\
\hline Utilization & $\begin{array}{l}\text { Using tool with success to open/crack nuts } \\
\text { during a session }\end{array}$ \\
\hline Reutilization & $\begin{array}{l}\text { Using one tool that another individual } \\
\text { selected before during a session }\end{array}$ \\
\hline Change tool function & Changing tool set during a session \\
\hline Fractured tool & Fracturing the tool during the session \\
\hline Reuse fractured tool & Reusing a tool after the previous fracture \\
\hline Flake extraction & $\begin{array}{l}\text { Producing unintentional flake extraction } \\
\text { during nut cracking }\end{array}$ \\
\hline Tool playing & Manipulation of stones for playing \\
\hline Discarding tool & $\begin{array}{l}\text { Combined record of tools that present } \\
\text { recent fracture, allowed refitting, never been } \\
\text { used during this experimental period }\end{array}$ \\
\hline
\end{tabular}

For utilization, we also observed individual, sex, and age differences. Yolo, Jeje, and Peley (PL, juvenile male) utilized more tools than did the others $\left(\chi^{2}=154.18, \mathrm{df}=10, p<0.01\right)$ (Fig. 4). Males utilized more tools than females $\left(\chi^{2}=48.42\right.$, $\mathrm{df}=1, p<0.01)$, and adults used more than did juveniles $\left(\chi^{2}=14.335, \mathrm{df}=1, p<0.01\right)$.

The associated use of one hammer with one anvil was analyzed to identify tool-set preferences. Spearman correlation indicates that some hammers were repeatedly combined with the same anvils $\left(r_{\mathrm{S}}=0.661, p<0.01\right)$. The tool sets that were combined most often were hammer 56 with anvil 57 $(n=47)$, hammer 17 with anvil $12(n=34)$, hammer 4 with anvil $8(n=27)$, and hammer 54 with anvil $53(n=17)$.

Juveniles showed more reuse than adults $\left(\chi^{2}=6.145\right.$, $\mathrm{df}=1, p=0.013)$. However, there were no differences in the ways that tools were changed or modified across age groups $\left(\chi^{2}=0.896, \mathrm{df}=1, p=0.344\right)$.

Discarding was analyzed by combining recent fractures, tool refitting, and absence of use during the experiments (Table 2). Of the 57 stones, 36 (63\%) showed signs of recent fracture and $26(46 \%)$ allowed refitting, showing that they had been used before. Of these 26 , ten $(17.5 \%)$ stones were never used and were considered discarded, and seven (12\%), although used, changed in function after fracture. Only those tools that remained within the mean values of hammer and anvil dimensions (width, length, height, and weight) were used again after fracture, with a new function (Table 4). All tools were used as hammers after fracturing, except tool number 53, which was used mainly as an anvil. The discarded tools were smaller than the utilized tools in width $(t=5.279$, $p<0.01)$, length $(t=4.443, p<0.01)$, height $(t=4.834$, $p<0.01)$, and weight $(t=5.265, p<0.01)$ (Table 5).

There was no evidence of a relationship between function and use-wear trace, with hammers and anvils showing both pitting and depressions marks $\left(r_{\mathrm{S}}=0.035, p=0.795\right)$, nor between function and shape $\left(r_{\mathrm{S}}=0.208, p=0.117\right)$.

Of the two episodes of unintentional flake extraction observed, one was notable: Jire produced a large flake from an anvil and then tried, briefly, to reuse the new flake as a hammer, unsuccessfully.

Table 2

Features analyzed in nut-cracking tools

\begin{tabular}{|c|c|}
\hline Tool & Description \\
\hline Measures & $\begin{array}{l}\text { (1) Width }(\max . \mathrm{cm}) \text { - diameter of the used surface (macrowear traces) at right angle to the length } \\
\text { (2) Length }(\max . \mathrm{cm}) \text { - - longest diameter of the used surface } \\
\text { (3) Height }(\max . \mathrm{cm}) \text {-highest axis at right angle to the length } \\
\text { (4) Weight }(\max . \mathrm{g})\end{array}$ \\
\hline Shape (approximated) & $\begin{array}{l}\text { (2) Spheroid } \\
\text { (3) Rectangular } \\
\text { (4) Square } \\
\text { 5) Semi spheroid } \\
\text { (6) Trihedral } \\
\text { (7) Trapezoidal } \\
\text { (8) Irregular }\end{array}$ \\
\hline Refitting & $\begin{array}{l}\text { (1) Allow refitting } \\
\text { (2) Don't allow refitting }\end{array}$ \\
\hline Macrowear traces & $\begin{array}{l}\text { (1) Pitting: Multiple impact points superficial, small, and circular } \\
\text { (2) Depression: One circular impact point, evidence of profundity whole } \\
\text { (3) Multiples traces: Presence of pitting and depressions } \\
\text { (4) No trace: No clear evidence }\end{array}$ \\
\hline Presence of flake (or chip) extraction & $\begin{array}{l}\text { (1) Yes } \\
\text { (2) No }\end{array}$ \\
\hline Tool mobility & $\begin{array}{l}\text { (1) Movable tool } \\
\text { (2) Nonmovable tool }\end{array}$ \\
\hline
\end{tabular}




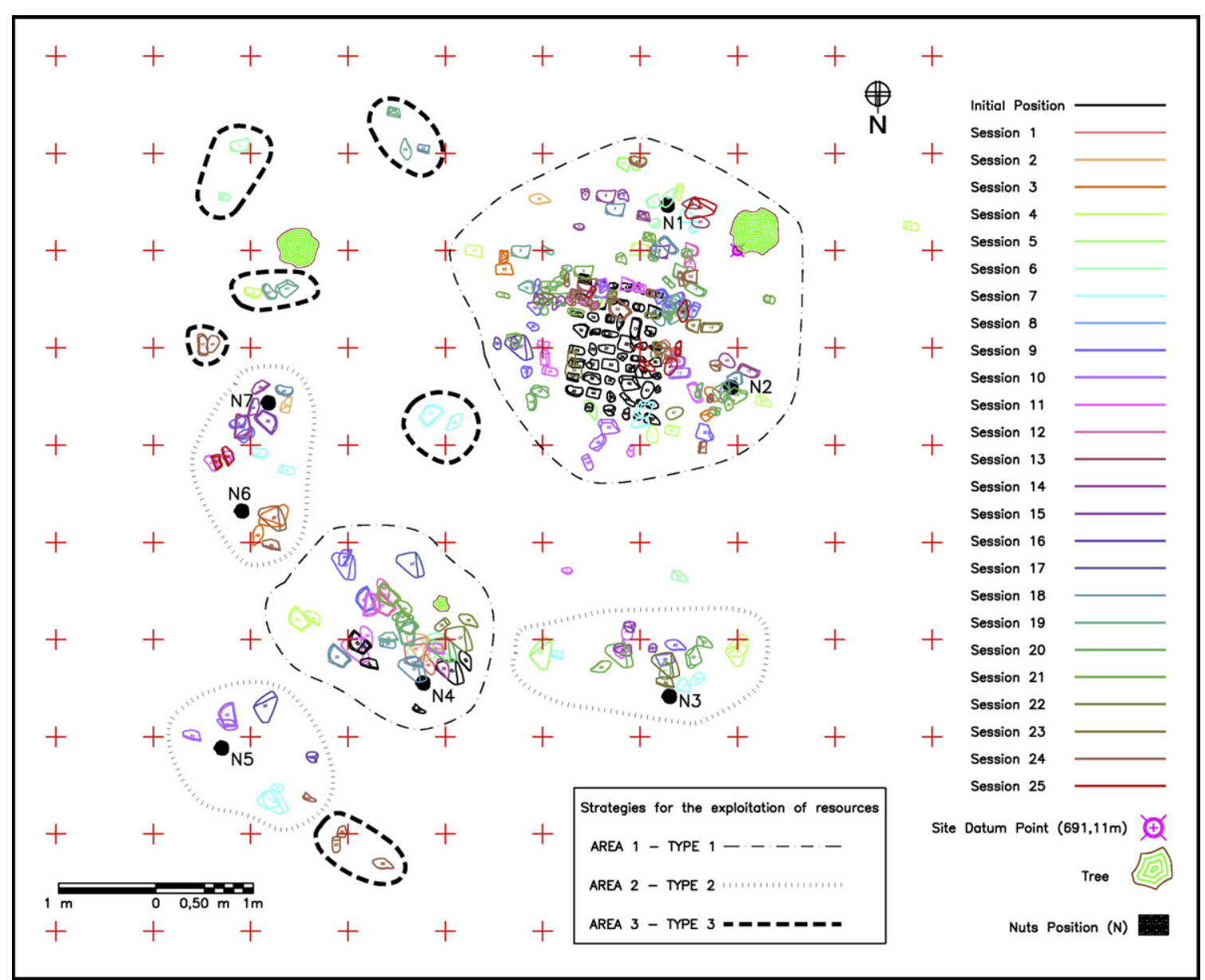

Fig. 3. Final composite drawing with all sessions inserted to examine spatial distribution of tools in the activity areas: Type 1-exploitation near both the rawmaterial source (stones) and the food source (nuts); Type 2-exploitation involving the transport of the raw material to the nuts; Type 3-exploitation involving the transport of stones and nuts to another site lacking both.

\section{Discussion}

Regarding availability of raw-material type (expected) vs. raw-material selection (observed), all diorite stones were used, although the most common raw material was granite. This suggests that chimpanzees may be selecting tools based on specific raw materials.

Most tools were used for one function, as either hammer or anvil. Mean dimensions of hammers and anvils show that chimpanzees discriminate based on tool features, such as width and weight. This shows that chimpanzees can distinguish morphological characteristics of these objects and therefore attribute to

Table 3

Pearson correlation ( $r$; two-tailed) between tool measures and function $(n=33)$

\begin{tabular}{|c|c|c|c|c|c|}
\hline & Tool width & Tool length & Tool height & Tool weight & $t$ Tool function \\
\hline Tool width & & $0.668^{* * *}$ & $0.624^{* * *}$ & $0.799 * *$ & $0.436^{*}$ \\
\hline Tool length & & & $0.584 * *$ & $0.788^{* *}$ & $0.490^{* *}$ \\
\hline Tool height & & & & $0.826^{* *}$ & $0.452 * *$ \\
\hline Tool weight & & & & & $0.496^{* *}$ \\
\hline
\end{tabular}

$* p<0.05$.

$* * p<0.01$ them a specific function. The results show an operational sequence with predominance of stone selection for tool construction, transport, and utilization. Males at Bosssou performed all the three nut-cracking activities more often than females.

As tools were placed near four piles of nuts (N1, N2 and N4, N5), chimpanzees could crack nuts without having to transport tools. Despite this condition, tools were often

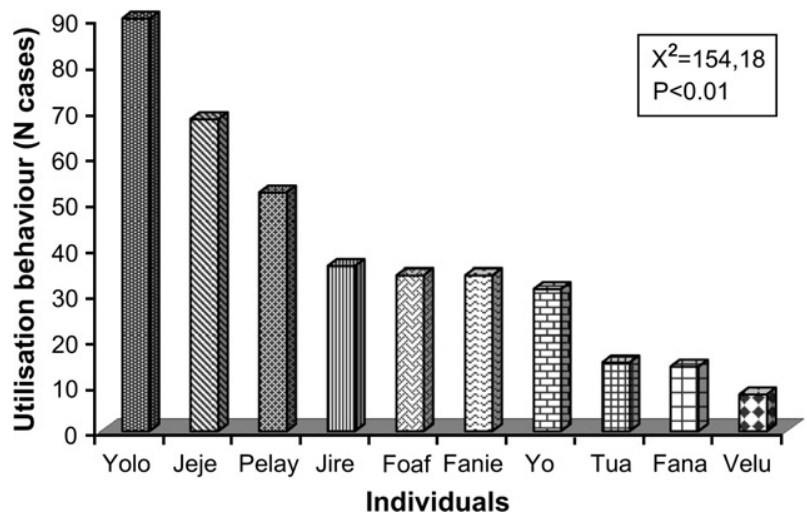

Fig. 4. Individual differences in the utilization of tools at the outdoor laboratory. 
Table 4

Mean values of width, length, height, and weight of hammers, anvils, and changed-function-after-fracture tools

\begin{tabular}{|c|c|c|c|c|c|c|}
\hline & \multicolumn{2}{|c|}{ Hammer } & \multicolumn{2}{|c|}{ Changed function after fracture } & \multicolumn{2}{|c|}{ Anvil } \\
\hline & Mean & SD & Mean & SD & Mean & SD \\
\hline Width $(\mathrm{cm})$ & 7.68 & \pm 1.49 & 8.37 & \pm 3.21 & 13.87 & \pm 1.14 \\
\hline Height $(\mathrm{cm})$ & 5.53 & \pm 1.48 & 6.07 & \pm 2.49 & 9.00 & \pm 2.45 \\
\hline Weight (g) & 683.00 & \pm 216.50 & 1065.90 & \pm 1230.30 & 3200.00 & \pm 1408.20 \\
\hline
\end{tabular}

transported to other spots. Hammers were transported more often than anvils. The size of the tool seems to have been an important determinant of transport. However, one of the tools that was moved the most was also the heaviest. This may reflect the existence of individual tool preferences or even a rudimentary form of possession (Matsuzawa, 1999).

Yolo, Jeje, and Peley (all males) used tools more often than the other group members. Utilization was recorded each time an individual used a tool during an experiment. For this reason, the high frequency in juveniles (Peley and Jeje) can also be a sign of difficulty in choosing an appropriate tool set. This explanation is also supported by the significant results for the reuse behavior among the juveniles. Juveniles often reused tool sets that had already been used by adults. Repeated associative utilization of one hammer with one anvil (e.g., hammer 56 with anvil 57, or hammer 17 with anvil 12) suggests that chimpanzees have tool-set preferences. This fact reinforces the perspective of the nutcracker as a unique tool complex composed of two or more elements.

Discarded tools can be identified by the morphological measures of the object after fracture. Chimpanzees discard tools after fracture, if the fracture modifies tool dimensions and the stones become too small to be effective as hammers or anvils. The changing function of a tool after fracture is also related to physical characteristics of the stone. Tools are used after fracture if the new tool remains in the range of mean values of hammers or anvils.

The lack of correlation between tool function and shape indicates that these are not decisive features that allow for distinguishing a hammer from an anvil.

\section{Drawing analysis - spatial analysis of chimpanzee nut cracking}

The composite drawing provides an overall spatial distribution of the tools (Fig. 3). Three types of resource-exploitation strategies emerged. The first type corresponds to area 1 -the place for maximum optimization and management of resources with the least investment of energy, as it is near both the raw-material source (stones) and the food source (nuts). The second type (area 2) involves the transport of the raw material to the nuts. At first, this may appear to be a non-optimization of resources, as tools are heavier than nuts. However, this may actually be an efficient strategy: when a pile of nuts is exhausted, it may be easier to carry a tool only once to another pile, as oppose to transporting nuts in several trips. The third type (area 3) is the transport of stones and nuts to another site, which lacks both. This suggests that the optimization and management of resources may also be affected by social constraints. It may be advantageous to carry stones and nuts to a less crowded site to avoid being disrupted.

\section{Phase 2: Bossou Forest-Moblim (SA 13)}

\section{Apparatus and method}

In Bossou Forest, eleven nut-cracking sites were monitored daily for chimpanzee visits. One, Moblim (SA 13), was visited six times between 6 March and 28 April 2006. The present analysis therefore focuses on this site. The same chimpanzees foraged at SA 13 as at the outdoor laboratory. The site's exact geographical location is $07^{\circ} 38^{\prime} 20.7^{\prime \prime} \mathrm{N}$; $008^{\circ} 30^{\prime} 39.2^{\prime \prime} \mathrm{W}$, at an altitude of $551 \mathrm{~m}$ (Fig. 1). The area had varied raw-material types: granite, quartz, quartzite, diorite, laterite, dolerite, and conglomerate. It was located under one oil-palm tree at the forest boundary. Oil-palm nuts were scattered around the palm in bunches on the ground (Fig. 5).

Video (132 min) and photographic records were made twice during the observation period, between March 2006 and May 2006. A survey was done around the oil-palm (ca. $15 \mathrm{~m}$ ) to seek potential tools. This baseline allowed the monitoring of any transport of new tools to the site. The original stones were coded as hammers $(\mathrm{H})$, anvils $(\mathrm{A})$, wedges $(\mathrm{W})$, and flakes $(\mathrm{F})$. The same archaeological method and apparatus

Table 5

Mean values of width, length, height, and weight of hammers, anvils, and discarded tools

\begin{tabular}{|c|c|c|c|c|c|c|}
\hline & \multicolumn{2}{|c|}{ Hammer } & \multicolumn{2}{|c|}{ Discarded tools } & \multicolumn{2}{|c|}{ Anvil } \\
\hline & Mean & SD & Mean & SD & Mean & SD \\
\hline Width (cm) & 7.68 & \pm 1.49 & 6.21 & \pm 1.15 & 13.87 & \pm 1.14 \\
\hline Length $(\mathrm{cm})$ & 11.91 & \pm 1.90 & 8.83 & \pm 2.11 & 17.20 & \pm 3.16 \\
\hline Height $(\mathrm{cm})$ & 5.53 & \pm 1.48 & 4.45 & \pm 0.89 & 9.00 & \pm 2.45 \\
\hline Weight (g) & 683.00 & \pm 216.50 & 343.90 & \pm 96.90 & 3200.00 & \pm 1408.20 \\
\hline
\end{tabular}


Table 6

Mean values and standard deviations of hammers and anvils recovered during Phases 1 and 2 of this study

\begin{tabular}{|c|c|c|c|c|c|c|c|c|}
\hline \multirow[t]{2}{*}{ Sites } & \multicolumn{2}{|c|}{ Length (cm) } & \multicolumn{2}{|c|}{ Width $(\mathrm{cm})$} & \multicolumn{2}{|c|}{ Height $(\mathrm{cm})$} & \multicolumn{2}{|c|}{ Weight $(\mathrm{kg})$} \\
\hline & Hammers & Anvils & Hammers & Anvils & Hammers & Anvils & Hammers & Anvils \\
\hline $\begin{array}{l}\text { Bossou outdoor laboratory } \\
\text { (present study) }\end{array}$ & $11.91 \pm 1.90$ & $17.20 \pm 3.16$ & $7.68 \pm 1.49$ & $13.87 \pm 1.14$ & $5.53 \pm 1.48$ & $9.00 \pm 2.45$ & $0.68 \pm 0.21$ & $3.2 \pm 1.4$ \\
\hline $\begin{array}{l}\text { Bossou Moblim SA13 } \\
\text { (present study) }\end{array}$ & $8.41 \pm 1.51$ & $11.75 \pm 2.89$ & $13.92 \pm 5.35$ & $16.24 \pm 3.88$ & $6.62 \pm 1.99$ & $6.30 \pm 2.49$ & $1.38 \pm 0.79$ & $2.1 \pm 0.78$ \\
\hline Bossou Forest (1991)* & $12.0 \pm 2.65$ & $16.1 \pm 6.47$ & $7.7 \pm 1.86$ & $11.1 \pm 4.38$ & $5.2 \pm 1.08$ & $7.3 \pm 2.97$ & $0.7 \pm 0.33$ & $2.2 \pm 2.21$ \\
\hline
\end{tabular}

* We also present the physical characteristics of tools from Bossou Forest measured by Sakura and Matsuzawa (1991).

as in Phase 1 were applied. Based on indirect evidence, recognition of tool functions relied on the detection of fresh traces on the stones. A stone positioned on top of the hardshelled debris was considered a hammer, while if the nuts were on top of the stone it was classed as an anvil. A wedge was defined as a stone being found in situ under the anvil. Flake extraction was recorded when the flake could be refitted to another tool. A sequential number, a function code, and an area marker were assigned to each stone (e.g. $2 \mathrm{H} \mathrm{M}$ for hammer number 2 from Moblim site). This allowed the tools to be recognized when they were found elsewhere. Stone selection for tool construction was recorded when the nutcracker was found in place, with hammer, anvil, or wedge together, or, when chimpanzees were observed directly, each time one individual used two or more stones together. Transport was checked by drawing the site during each visit. Utilization was considered to have occurred each time a tool showed fresh-food residue or, when the tool use was observed directly (each time an individual used a tool successfully).

\section{Results}

All tools were movable (100\%) and were made of three raw materials: granite, quartz, or diorite. Granite was used more often when compared with the other raw materials $\left(\chi^{2}=\right.$ 54.83, $p<0.01)$.

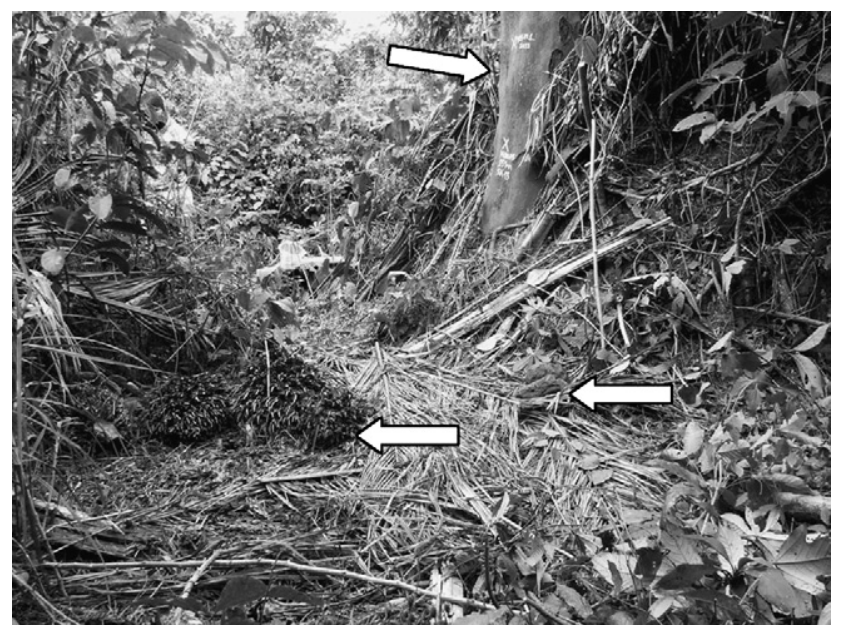

Fig. 5. Moblim nut-cracking site (SA 13): arrows indicate the oil-palm tree (at the back), the nut bunches (left), and the hammer and anvil (right).
Tool and function were correlated $\left(r_{\mathrm{S}}=0.260, p=0.002\right)$. Tools classified as anvils showed the highest mean values for width, length, and weight. Hammers and anvils differed in width $(t=2.829, p<0.01)$, length $(t=7.983, p<0.01)$, and weight $(t=5.407, p<0.01)$, but not in height $(t=0.805$, $p=0.422)$. Wedges $(n=3)$ and tools of unknown function $(n=2)$ did not differ in width $(t=0.185, p=0.858)$, length ( $t=0.681, p=0.515)$, height $(t=0.730, p=0.486)$, or weight $(t=0.288, p=0.781)$. At the Moblim site, tools $(n=19)$ were mainly (79\%) used for one function only, as in Phase $1(73 \%)$. Only four tools $(21 \%)$ served both functions.

The main stages of the operational-sequence behaviors were present: stone selection for tool construction $(n=48)$, transport $(n=38)$, utilization $(n=51)$, and unintentional flake extraction $(n=1)$. Stone selection for tool construction did not differ from the experiments $\left(\chi^{2}=0.524, p=0.969\right)$. One case of using two wedges to stabilize an anvil was seen, yielding a composite tool of four stones (two wedges, hammer, and anvil), and so the sequential combination of five elements during tool use (four stones and one nut) (Fig. 6).

Transport was no more frequent than in Phase 1 $\left(\chi^{2}=0.006, p=0.933\right)$. Hammers and anvils were transported equally often $\left(\chi^{2}=0.118 ; \mathrm{p}=0.732\right)$, but wedges were transported less often than other tools $\left(\chi^{2}=9.053, p=0.011\right)$. Tool utilization in the wild did not differ from the experimental sessions $\left(\chi^{2}=1.006, p=0.315\right)$. In macro-use-wear analyses, tools used with a specific function (hammer or anvil) tended to

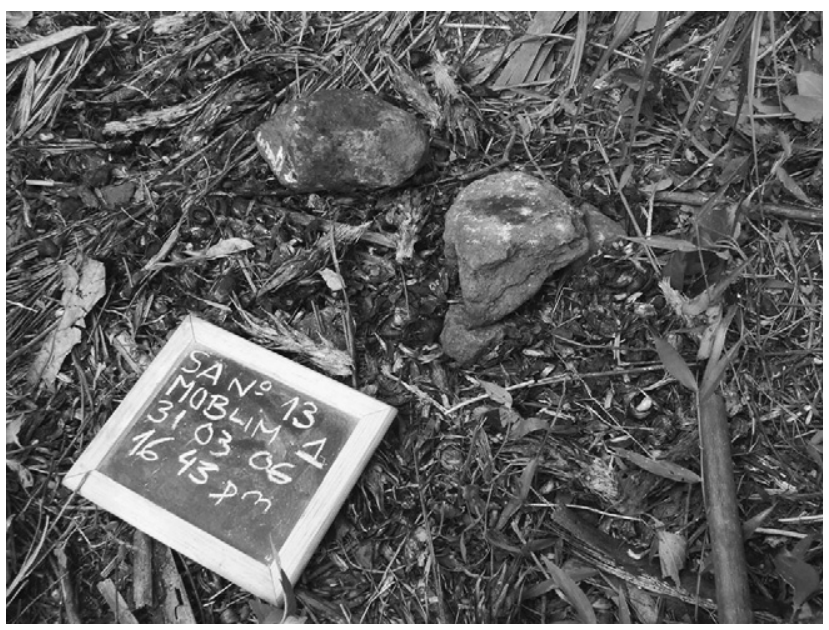

Fig. 6. The construction of a composite tool with four stones: two wedges, a hammer and an anvil. 
be more pitted than wedges and tools used indiscriminately $\left(r_{\mathrm{S}}=0.456, p=0.05\right)$. Again, tool shape was not correlated with tool function $\left(r_{\mathrm{S}}=0170, p=0.487\right)$.

\section{Discussion}

The common use of granite tools may reflect the great availability of granite in Bossou Forest, but further experiments to evaluate this variable are needed. For tool function, the results from Phase 1 were confirmed. Of 19 tools, only four were used for more than one function, and of these, two had atypical dimensions. Chimpanzees seem to attribute functions to stones as hammers and anvils according to their weight, width, and length, confirming the findings of Sakura and Matsuzawa (1991). The tool's height is not a discriminative feature, perhaps making it the least important characteristic in the selection of an efficient hammer or anvil. Given that wedges and unknown tools show no differences, the latter could be used as wedges.

Stone selection for tool construction and utilization was detectable by indirect means. Several nutcrackers were recorded in the drawings, providing the details of the uses and the final tool movements after chimpanzees visited. Transport was clearly identified: Not only were tools transported inside the area, but new tools were also brought in by the chimpanzees. The initial sample of nine tools grew to 19. Transport seems not to depend upon the availability of the raw material: New tools were brought to the site and were used instead of the tools already there and equally close to the food source. This echoes the existence of transport in Phase 1. In Moblim, the anvils show lower average weights, which may explain the equal transport of hammers and anvils.

The lack of relationship between tool function and tool shape confirms the previous results. Macrowear traces were found, indicating that the tools were used for a long time; this was congruent with the observed reuse of the same tools. Flake extraction occurred once, during the last observation. At the Moblim site, no tool fracture occurred, and thus no verification of the behavioral variables "reusing tool after fracture" and "changing function after fracture" was possible. Patterns were indirectly recorded and confirmed, with refitting at a different nut-cracking site in the Bossou area (Breton SA 12: $07^{\circ}$ $38^{\prime} 20.7^{\prime \prime} \mathrm{N}$; $\left.008^{\circ} 30^{\prime} 39.2^{\prime \prime} \mathrm{W}\right)$. One large flake was extracted from an anvil and was then reused as a hammer (Fig. 7).

As in Phase 1, using direct and indirect observations, we could confirm the existence of a repeated operational sequence during nut cracking by wild chimpanzees.

\section{Drawing analysis - spatial analysis of chimpanzee nut cracking}

Spatial distribution of tools after six visits shows the existence of various activity areas for nut cracking. These activity areas match three types of resource-exploitation areas (Fig. 8). The first type (area 1) was nearest to the food source (oil palm) and the raw-material source (stones located near the oil palm). This site was repeatedly used by the chimpanzees to crack nuts. The second type (area 2) entailed the repeated transport of raw material to a bunch of nuts, after having transported the bunch. This optimization of resources resembles the carrying of the tools to the piles of nuts in stage one. The third type (area 3) comprised six other nut-cracking sites, implying the transport of tools and collected nuts (taken from the bunch) to more isolated areas. This strategy reflects social constraints imposed on several individuals feeding at the same time.

\section{Phase 3-Diecké Forest (SB1)}

\section{Apparatus and method}

Site preparations to record tool movements and characteristics, including refitting, were done in Diecké Forest, as described in previous sections. One of the six recorded sites, Diecké SB1 (07 33'57.4" N; 009 $\left.02^{\prime} 07.1^{\prime \prime} \mathrm{W}\right)$, was visited by the chimpanzees during the study period.

The area of Diecké SB 1 is used by an unknown number of chimpanzee groups. Diecké's geology is generally the same as that of Bossou Forest, with the same raw-material types present, although granite is more abundant.

Site SB 1 was near one Panda oleosa tree and one watercourse. Fruits were dispersed around the area, and nut debris was concentrated around the outcrop anvils. The tools originally found are represented in the archaeological drawing according to the function recognized for each tool: hammer $(\mathrm{H})$ and anvil (A). The site's datum point $(426,80 \mathrm{~m})$ was fixed on a wellpositioned tree. Procedures for the indirect observation were as given in Phases 1 and 2. As the anvils were boulders, the tool dimensions recorded were width and length only.

\section{Results}

Tools were mostly made from granite $(n=16)$, with only one hammer made from quartz $(n=1)$. All anvils $(n=6)$ were nonmovable tools of outcropping rocks.

Tools functioning as anvils were larger $(r=0.864, p<0.01)$ and longer $(r=0.814, p<0.01)$ than hammer tools. Comparing the width and length of hammers and anvils used only for one function among the three study areas indicates variation. In Phase 1, hammers were thinner and larger than the hammers in Phase $2(t=13.809, p<0.01)$. Phase 1 hammers were thinner and shorter than those from Diecké SB1 $(t=13.006$, $p<0.01)$. Hammers from Phase 2 were larger and shorter than the Diecké hammers $(t=11.643, p<0.01)$, and larger and shorter than the Phase 1 tools $(t=11.643, p<0.01)$.

Anvils also differed across the three sites. The Diecké anvils were the largest and longest when compared with the Phase 1 $(t=6.974, p<0.01)$ and Phase 2 anvils $(t=7.31, p<0.01)$.

We also inferred several elements of the operational sequence: stone selection for tool construction $(n=17)$, transport $(n=1)$, utilization $(n=16)$, and fracture tool $(n=1)$ were recorded at Diecké. Tool shape and tool function were correlated $\left(r_{\mathrm{S}}=0.464, p<0.05\right)$. The hammers had an ovate or rectangular shape and anvils were rectangular or irregular. Macro-use-wear and tool function were uncorrelated $\left(r_{\mathrm{S}}=\right.$ $0.181, p=0.298)$. 

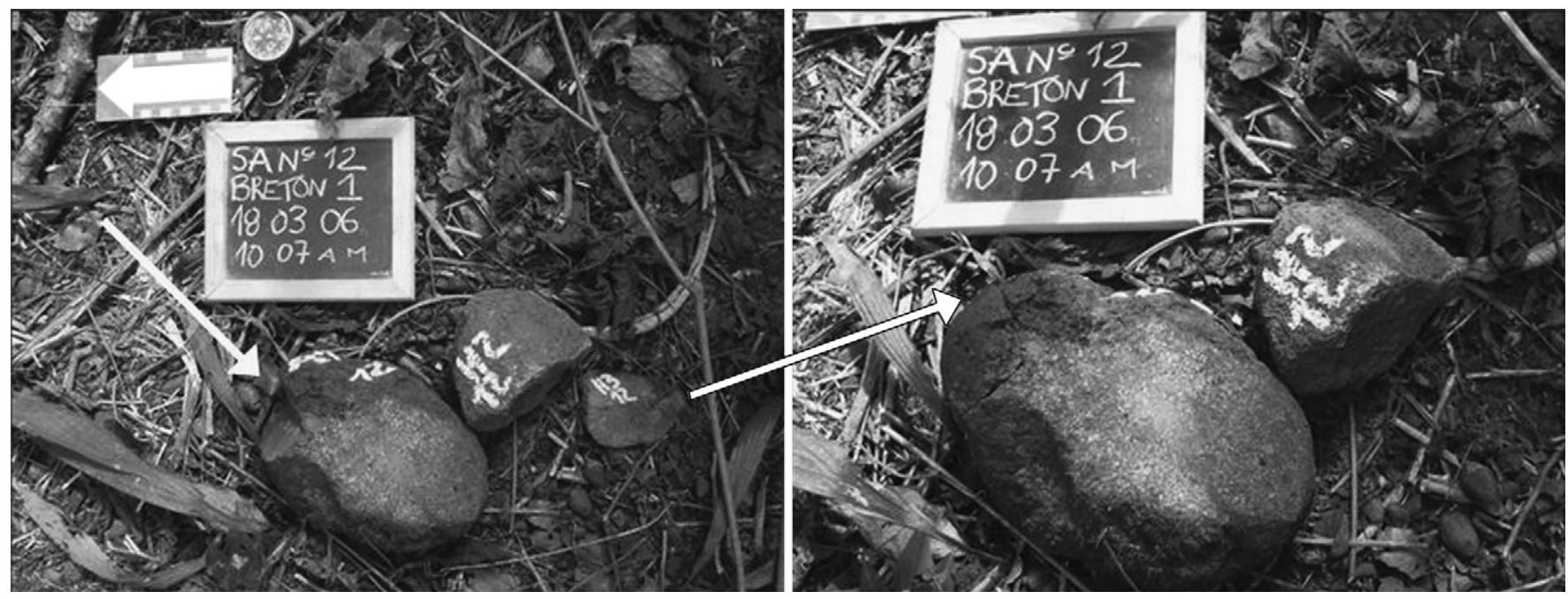

Fig. 7. The refitting example of a large flake extracted from an anvil and subsequently reused as a hammer (recorded in Breton SA 12 [Bossou] while monitoring the nut-cracking site).

\section{Discussion}

Most of the Diecké tools were made of granite. The single quartz hammer was probably carried from the watercourse next to the site (Lilaya), which is the nearest source of quartz stones.

All of the stone tools recorded at Diecké served only one function. Only one episode of tool transport was recorded at
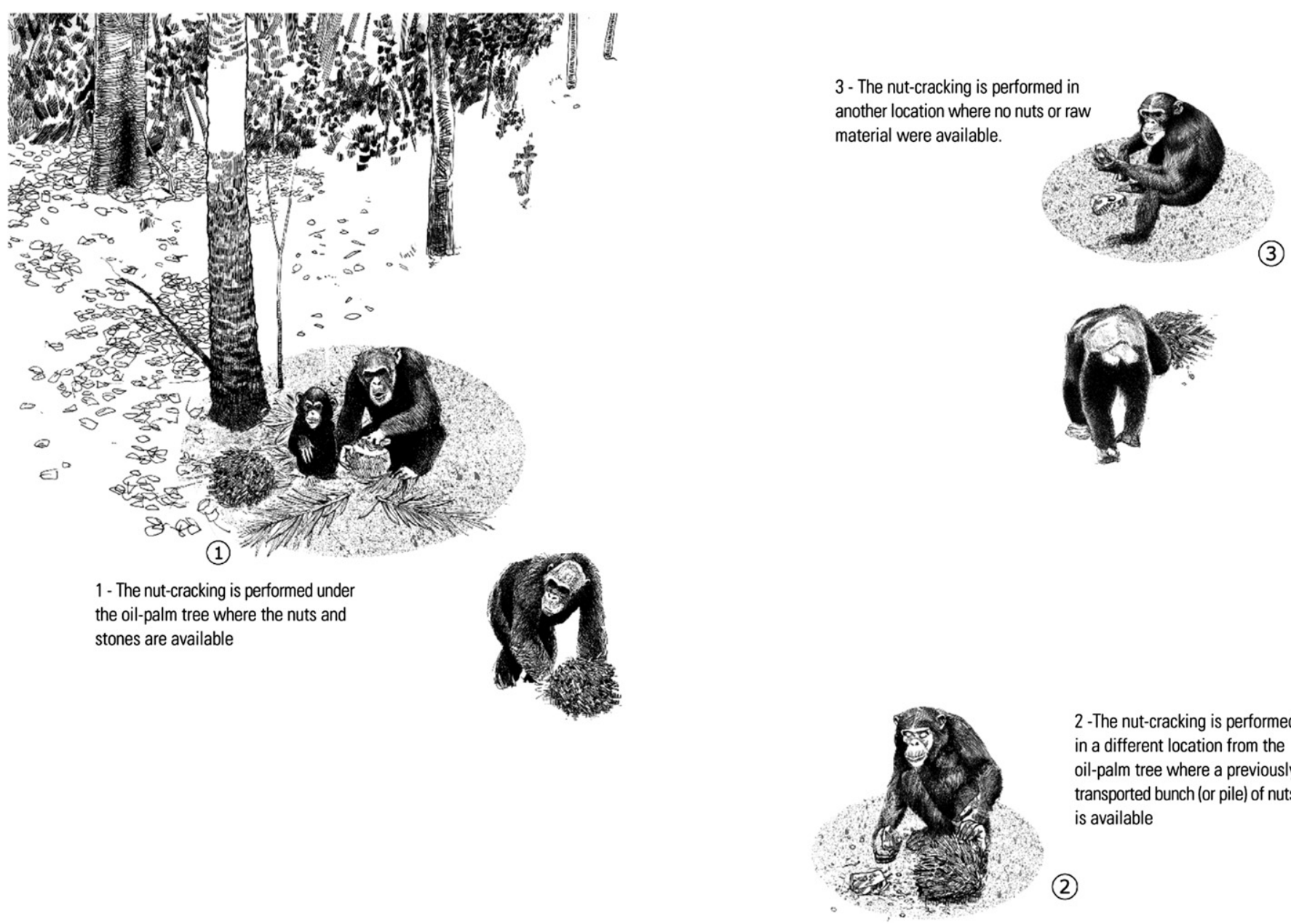

2 -The nut-cracking is performed in a different location from the oil-palm tree where a previously transported bunch (or pile) of nuts is available

Fig. 8. The three types of resource exploitation performed during nut cracking by wild chimpanzees. 
the site, and thus little can be said about transport frequency. Anvils observed at Diecké served only this function, as all were nonmovable. This may be a limitation for technological development. Differences between the dimensions of anvils and hammers suggest that Diecké chimpanzees attribute function to each tool. In Diecké, hammers were longer and the anvils bigger than those at the other two studied sites. Since Panda oleosa is a very hard nut to crack, chimpanzees must select tools according to the characteristics of the consumed food. The use of these large and embedded anvils may increase the efficiency of cracking the hard Panda nuts, and thus decrease the energy investment needed to carry large, movable anvils. This demonstrates a capacity to adapt to environmental constraints, as movable tools in the primary forest may be few. The relation between function and shape indicates that hammers are easier to handle if they are rectangular or ovate. The results show that chimpanzees are using the available outcropping rocks as anvils for nut cracking. The large and flat surfaces provided by these rocks may be the most important characteristics for this selection.

All the main phases of the operational sequence were found. The tool transported during this visit was hammer number 2. This was transported to anvil number 3, while two other potential hammers were next to anvil 3 .

\section{General discussion}

\section{Nut cracking and nutcracker: tool use and} tool construction?

Archaeology adds new insights to the primatological treatment of tool use. In functional analysis, the goals are to determine how a tool was used and identify the materials that were worked with it (Semenov, 1981). Hammers and anvils at Bossou and Diecké showed use-wear traces (e.g., pitting, depression), suggesting extended use and reuse. Use wear may thus be an important variable for defining tool function and successful technology, as noted by Karlin and Pelegrin (1988: 823) in their definition of a tool: "intentionally (or purposefully) made objects, or any natural object or knapping debris which show use wear at the macro or micro scale." For tool analysis, and according to the operational sequence defined in this study, a sub-behavioral routine was stone selection for tool construction (Table 1). To process nuts, a hammer plus an anvil create a nutcracker. They are objects combined in sequence (Matsuzawa, 1996), which thereby creates another tool: hammer and anvil do not work if separated from one another. Thus, tool construction is the purposeful association of two or more objects (transformed or not) that need to be used in combination in order to function and achieve a specific goal. This study indicates that chimpanzees preferentially combine certain hammers with anvils when composing a nutcracker, as indicated by the Phase 1 results. This reinforces the perspective of the nutcracker as a single tool. The most complex and technologically developed nutcracker in the wild, constructed with two, three, or even four elements, was found in Bossou, corresponding to techno-units of different complexities (Oswalt, 1976). According to Matsuzawa's (1996) tree-structure model representing the hierarchical levels of chimpanzee tool-use behavior, the recorded nutcracker constructed with four stones could represent a "Level Four" tool. This adds one degree of complexity to tool use observed in the wild so far, as this tool entails the sequential combination of five elements: two wedges, one hammer, one anvil, and one nut.

Overall comparison of the tools analyzed at the three sites suggests regional diversity in stone-tool typology and technology: (1) hammers and anvils are larger at Diecké that at Bossou; (2) all tools were movable at Bossou; no anvils were movable at Diecké; (3) outcropping rocks at Bossou were used only rarely to crack nuts (however, at Bossou these outcropping rocks were often of transformed or weathered granite, with so much magnesium/iron elements that the tool fractured or disaggregated quickly); (4) Diecké Forest had few movable stones in its core. Given its large and stable outcropping of "anvils" near the food source, searching for other anvils was unnecessary.

Chimpanzee stone hammers did not fit the predetermined morphological values for "chimpanzee hammers" or "hominin hammers," as given by Mercader et al. (2007). At Bossou, to process the oil-palm nuts, chimpanzees used smaller hammers with dimensions similar to the so-called "hominin hammers," while in Diecké, to process the hard Panda nuts, chimpanzees selected larger hammers. These different tool sizes show an optimal combination of raw material, size, and weight with typological and technological adaptations. This combination reflects the type of food consumed and the type of raw material available and so cannot serve as a feature for distinguishing hominin from chimpanzee tools. Raw-material availability and tool mobility are two possible ecological constraints on technological development in human and nonhuman tool use. Although chimpanzees in Diecké (Matsuzawa, 1999; Humle and Matsuzawa, 2001), Taï (Boesch and Boesch, 1990; Boesch and Boesch-Achermann, 2000), and Cameroon (Morgan and Abwe, 2006) crack nuts, none of these sites has so far shown a tool as elaborate as at Bossou. Wedge use can only appear when anvils consist of movable materials.

\section{Chaîne opératoire and resource-exploitation strategies}

The operational sequence of tools used by wild chimpanzees was confirmed at three nut-cracking sites in Guinea. Through direct and indirect observation, all stages of the construction and effective use of a tool were recognized. This provided a nut-cracking ethogram, which allows detection of elements from any one of the stages (e.g., tool transport). Nut cracking by chimpanzees at Bossou is characterized by a series of steps comprising different actions, performed repeatedly to achieve a predetermined goal (Fig. 9). Chimpanzees made choices during nut cracking and performed it in several modes. They skipped some steps or extended the sequence, while maintaining the main stages that led to the tools being discarded, creating a stone assemblage. This reflects their capacity for adaptation, flexibility, 


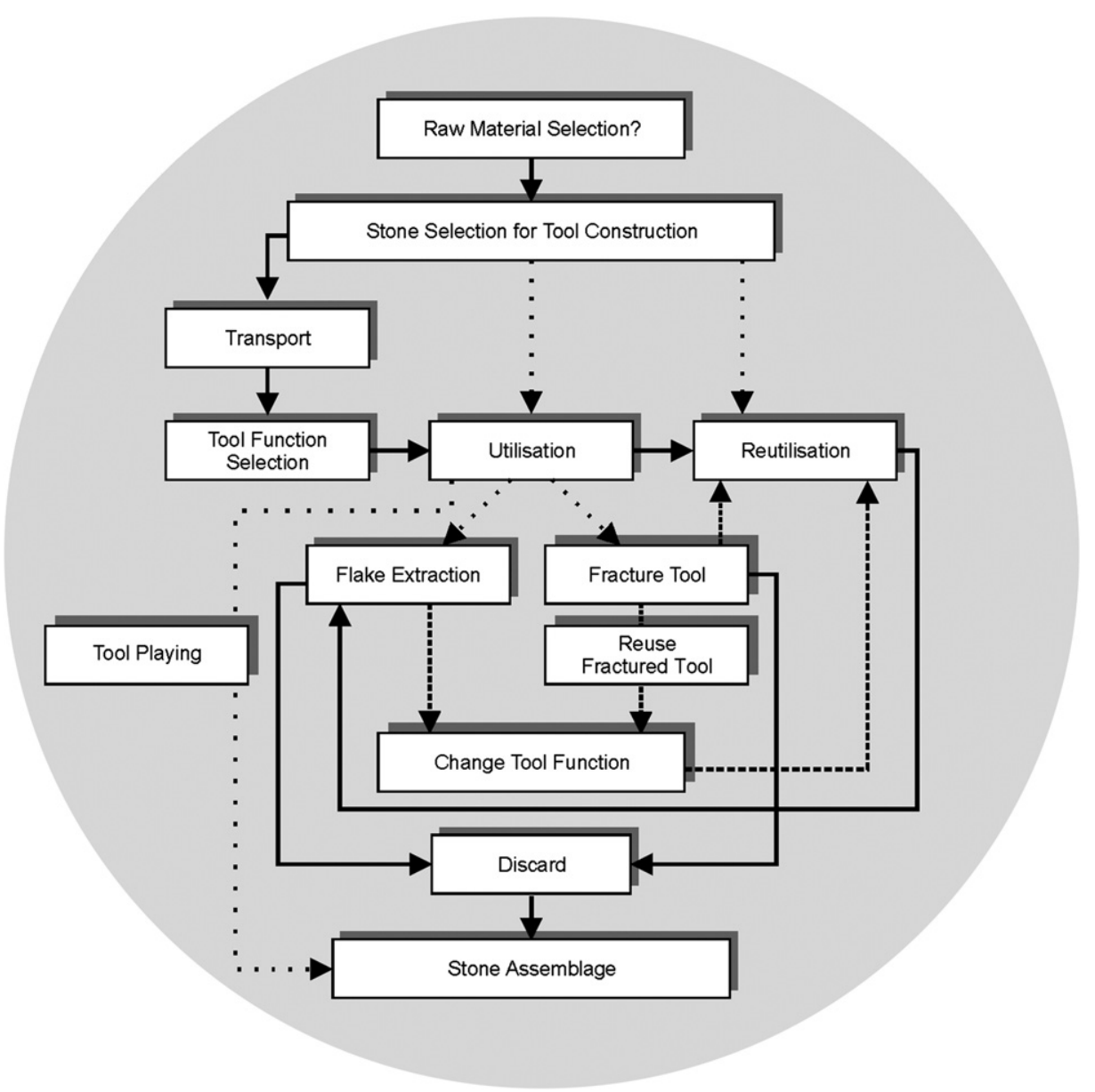

Fig. 9. Schematic diagram of the operational-sequence structure, representing the possibilities of the sequential nut-cracking sub-behaviors, observed during this study. The sequence begins at the top and follows the arrows: the solid lines represent the fundamental phases of the operational sequence (i.e., those phases that have to occur in order to complete a whole sequence-from the selection of the raw material to the final discard of the tool leading to the formation of a stone assemblage - and simultaneously those that allow the individual to reach the goal: cracking the nut for consumption) observed during nut cracking; the dotted lines represent other recorded possibilities of performing the sequence by bypassing some phase, thus making the sequence shorter; the dashed lines represent the recorded possibilities of a longer and more complex sequential chain of the nut-cracking behaviors; the question mark indicates that the cause of this behavior has not been inferred.

and optimization of tasks (Sakura and Matsuzawa, 1991). Chimpanzees discriminated tool functions based on tool features, selecting optimal sizes and weights, which confirms previous results at Bossou (Sugiyama, 1981; Kortlandt and Holzhaus, 1987; Sakura and Matsuzawa, 1991) and in Taï (Boesch and Boesch, 1982).

The lack of relationship between shape and function is notable, given the importance of morphology in archaeological typologies. The absence of this relationship is pertinent to studies of early Oldowan industries, as it raises the possibility that other characteristics, such as size, may be more indicative of tool function than shape.

For macrowear analysis, three conclusions emerge: (1) the tools showed traces of use that indirectly differentiate one stone from another tool; (2) use-wear traces show that the tools have been reused for a long time; and (3) since no relationship was found between the traces and the function, a micro-usewear analysis needs to be undertaken on the chimpanzee tools in order to explore additional possibilities. Transport of tools was confirmed at both the experimental site and the natural sites. Rate of transport can only be properly evaluated when combining direct and indirect records. An indirect observation reveals the last place where the tool was left, but it does not show how many movements occurred during the nut-cracking process. This may underestimate the real frequencies of tool transport by wild chimpanzees. A combination of methods from diverse disciplines is needed to reach a broader understanding of tool use by nonhuman primates.

Macrowear traces and frequency of tool transport give insights into the importance of transport in the nut-cracking process. In Phase 2, ten new tools appeared at the site, despite raw material being available nearby. During Phase 1, transport of the tools given to the chimpanzees was common. Thus transport is related not only to natural-resource availability, but also to tool preferences or tool possession (Matsuzawa, 1999). The distances of transport may not be needed to understand the complexity of this behavior, as distance can be imposed by the location of the next resource. Understanding 
why transport occurs when it is not apparently necessary to reach the goal is a challenge. At the natural nut-cracking site, chimpanzees transported hammers and anvils equally, while, at the experimental site, hammers were transported more often than were anvils. For the experiments, the stones were selected by humans, and the anvils were heavier than those recorded at the natural site.

Spatial analysis of the chimpanzees' nut cracking suggests that there is more than one type of resource-exploitation strategy (Fig. 8), as identified through the analysis of daily drawings of tool movements. This echoes the optimization of time and management of energy investment that constrains the social lives of chimpanzees (Boesch and Boesch, 1982). There were three distinct types: (1) maximum optimization of time and energy investment by exploiting resources closest to the food source; (2) transport of nuts to a different site or transport of the raw materials for tools to the food (it seems more efficient to transport the stones only once rather than transport the nuts several times); (3) transport of tools and food to a more distant spot could be a social strategy, related to sharing of space and resources when various individuals occupy the same area. This suggests affinities to Oldowan strategies because both are flexible, dynamic, opportunistic, and low-energy strategies to solve problems (Kimura, 1999). The three strategies appeared in both the experimental and the natural nut-cracking sites.

Mercader et al. (2002) referred to activity areas but did not mention differential resource-exploitation strategies performed by wild chimpanzees. The lack of mobility of some anvils may represent an ecological constraint to optional strategies. This study may also shed light on three of the nine important questions on the uniqueness of human culture raised by Davidson and McGrew (2005: 812): (1) "Do chimpanzees carry rocks as anvils for nutting?" (2) "Are there examples of apes recruiting tools, or tool-making processes, from one function to another?" (3) "What is the sequence of actions leading to the transport by chimpanzees of stone hammers for nutting?"

Regarding the first question, Bossou chimpanzees transport hammers and anvils for nut cracking. As for the second question: production of a large flake from an anvil that was later reused as a hammer shows that chimpanzees in nature can reuse a stone tool made from another stone tool. Although this production is unintentional, it does involve one tool being produced from another and then being reused with a different function. Experiments show that when one tool fractures during use, it may be reused with a different function when the new size fits a new function. Or, it may be discarded when the raw material fractures and results in an inadequately sized stone for nut cracking. Regarding the third question: the chimpanzees showed a sequence of repeated behavioral elements that led to tool transport and to nut-cracking action (Fig. 9).

Bossou chimpanzees may "act as a proxy in our evolutionary scenarios" (McGrew, 2004: 39) since they systematic use stone tools for nut cracking, and they use portable raw materials may permit increased technological complexity. Detection of the three types of exploitation strategy emphasizes the existence not only of operational sequences during the practice of nut cracking by wild chimpanzees, but also of strategic choices for acquiring and managing resources. These findings may have important implications for the future modeling of the technological evolution of early hominins.

\section{Acknowledgements}

We thank the Direction National de la Recherche Scientifique et Technique, République de Guinée, for permission to conduct field work at Bossou and Diecké. The research was supported by Grants-in-Aid for scientific research from the Ministry of Education, Science, Sports, and Culture of Japan: MEXT-16002001, JSPS-HOPE, JSPS-21COE-Kyoto-Biodiversity, and F-06-61 of the Ministry of Environment, Japan; and by the Grant Statute of the Municipality of Leiria, Portugal. We also thank Luis da Silva for the illustration and Luis Pinela for support with the GIS database. We thank Bonifas Zogbila, Henry Gbelegbe, Gilles Doré, Pascal Goumy, Marcel Doré, Jean Marie Kolié, Jnakoi Malamu, Louti Tokpa, Albert Kbokmo, Cé Koti, Onoré Mamy, Ouo Mamy, and Fromo Mamy for field support. We are grateful to F. Almeida, N. Bicho, D. Biro, E. Loureiro, W.C. McGrew, and three anonymous reviewers for helpful comments on an earlier version of the manuscript. This paper is dedicated to all the people who contributed to research at Bossou during the last 30 years.

\section{References}

Almeida, F., 2000. The terminal Gravettian of Portuguese estremadura: technological variability of the lithic industries. Ph.D. Dissertation, Southern Methodist University, Texas.

Anderson, J.R., Williamson, E.A., Carter, J., 1983. Chimpanzees of Sapo Forest, Liberia: Density, nests, tools and meat-eating. Primates 4, 594-601.

Backwell, L.R., d'Errico, F., 2001. Evidence of termite foraging by Swartkrans early hominids. Proc. Natl. Acad. Sci. U.S.A. 98, 1358-1363.

Bar-Yosef, O., Vandermeersch, B., Arensburg, B., Belfer-Cohen, A., Goldberg, P., Laville, H., Meignen, L., Rak, Y., Speth, J.D., Tchernov, E., Tillier, A.-M., Weiner, S., 1992. The excavations in Kebara Cave, Mt. Carmel. Curr. Anthropol. 33, 497-550.

Beatty, H., 1951. A note on the behaviour of the chimpanzee. J. Mammal. 32, 118.

Binford, L.R., 1980. Willow smoke and dog's tails: Hunther-gatherer settlement systems and archaeological site formation. Am. Antiq. 45, 4-20.

Biro, D., Inoue-Nakamura, N., Tonooka, R., Yamakoshi, G., Sousa, C., Matsuzawa, T., 2003. Cultural innovation and transmission of tool use in wild chimpanzees: Evidence from fields experiments. Anim. Cog. 6, 213-223.

Biro, D., Sousa, C., Matsuzawa, T., 2006. Ontogeny and cultural propagation of tool use by wild chimpanzees at Bossou, Guinea: Case studies in nutcracking and leaf folding. In: Matsuzawa, T., Tomonaga, M., Tanaka, M. (Eds.), Cognitive Development in Chimpanzees. Springer, Tokyo, pp. 476-508

Boëda, E., Geneste, J.-M., Meignen, L., 1990. Identification de chaînes opératoires lithiques du paléolithique ancient et moyen. Paleo 2, 43-80.

Boesch, C., 1996. The emergence of cultures among wild chimpanzees. In: Runciman, W.G., Maynard-Smith, J., Dunbar, R.L.M. (Eds.), Evolution of Social Behaviour Patterns in Primates and Man. Oxford University Press, New York, pp. 251-268.

Boesch, C., Boesch, H., 1982. Optimisation of nut-cracking with natural hammers by wild chimpanzees. Behaviour 83, 265-286.

Boesch, C., Boesch, H., 1984. Mental map in wild chimpanzees: an analysis of hammer transports for nut cracking. Primates 25, 160-170. 
Boesch, C., Boesch, H., 1990. Tool use and tool making in wild chimpanzees. Folia Primatol. 54, 86-99.

Boesch, C., Boesch-Achermann, H., 2000. The Chimpanzees of the Tai Forest-Behavioural Ecology and Evolution. Oxford University Press, New York.

Bordes, F., 1961. Typologie du Paléolitique Ancien et Moyen. Éditions CNRS, Paris.

Byrne, R.W., 1995. The Thinking Ape: Evolutionary Origins of Intelligence. Oxford University Press, Oxford.

Byrne, R.W., 1996. Machiavellian intelligence. Evol. Anthropol. 5, 172-180.

Byrne, R.W., 2007. Culture in great apes: Using intricate complexity in feeding skills to trace the evolutionary origin of human technological process. Phil. Trans. R. Soc. 362B, 577-585.

Byrne, R.W., Byrne, J.M.E., 1993. Complex leaf-gathering skills of mountain gorillas (Gorilla g. beringei): Variability and standardization. Am. J. Primatol. 31, 241-261.

Caldecott, J., Kapos, V., 2005. Great ape habitats: Tropical moist forests of the old world. In: Caldecott, J., Miles, L. (Eds.), World Atlas of Great Apes and Their Conservation. University of California Press, California.

Clark, J.D., 1967. The Atlas of African Prehistory. University of Chicago Press, Chicago.

Davidson, I., McGrew, W.C., 2005. Stone tools and the uniqueness of human culture. J. R. Anthropol. Inst. 11, 793-817.

d'Errico, F., Backwell, L.R., Berger, L.R., 2001. Bone tool use in termite foraging by early hominids and its impact on our understanding of early hominid behaviour. S. Afr. J. Sci. 97, 71-75.

Fushimi, T., Sakura, O., Matsuzawa, T., Ohno, H., Sugiyama, Y., 1991. Nutcracking behaviour of wild chimpanzees (Pan troglodytes) in Bossou, Guinea (West Africa). In: Ehara, A., Kimura, T., Takenaka, O., Iwamoto, M. (Eds.), Primatology Today. Elsevier, Amsterdam, pp. 695-696.

Goodall, J., 1964. Tool-using and aimed throwing in a community of freeliving chimpanzees. Nature 201, 1264-1266.

Goren-Inbar, N., Sharon, G., Melamed, Y., Kislev, M., 2002. Nuts, nutcracking, and pitted stones at Gesher Benot Ya'aqov, Israel. Proc. Natl. Acad. Sci. U.S.A. 99, 2455-2460.

Hannah, A., McGrew, W.C., 1987. Chimpanzees using stones to crack open oil palm nuts in Liberia. Primates 28, 31-46.

Heaton, J.L., Pickering, T.R., 2006. Archaeological analysis does not support intentionality in the production of brushed ends on chimpanzee termiting tools. Int. J. Primatol. 27, 1619-1633.

Humle, T., Matsuzawa, T., 2001. Behavioural diversity among the wild chimpanzee populations of Bossou and neighbouring areas, Guinea and Cote d'Ivoire, West Africa: A preliminary report. Folia Primatol. 72, 57-68.

Humle, T., Matsuzawa, T., 2004. Oil palm use by adjacent communities of chimpanzees at Bossou and Nimba mountains, West Africa. Int. J. Primatol. 25, 551-581.

Inoue-Nakamura, N., Matsuzawa, T., 1997. Development of stone tool use by wild chimpanzees (Pan troglodytes). J. Comp. Psychol. 111, 159-173.

Jardón Giner, P.J., 1990. La metodología del análisis traceológico y su aplicación a conjuntos líticos prehistóricos, vol. 23. Universidad de Valencia, Saguntum, pp. 9-36.

Joulian, F., 1996. Comparing chimpanzee and early hominid techniques: Some contributions to cultural and cognitive questions. In: Mellars, P., Gibson, K. (Eds.), Modelling the Early Human Mind. McDonald Institute Monographs, Cambridge, pp. 173-189.

Karlin, C., Pelegrin, J., 1988. Outil. In: Leroi-Gourhan, A. (Ed.), Dictionnaire de la Préhistoire. Quadrige, Presses Universitaires de France, Paris, p. 823.

Karlin, C., Bodu, P., Pelegrin, J., 1991. Processus techniques et chaînes opératoires, comment les préhistoriens s'approprient un concept élaboré par les ethnologues. In: Balfet, H. (Ed.), Observer l'Action Technique des Chaînes Opératoires, Pour Quoi Faire? Matières et Manières. Éditions CNRS, Paris.

Kimura, Y., 1999. Tool-using strategies by early hominids at Bed II, Olduvai Gorge, Tanzania. J. Hum. Evol. 37, 807-831.

Kormos, R., Humle, T., Brugière, D., Fleury-Brugière, M., Matsuzawa, T., Sugiyama, S., Carter, J., Diallo, M.S., Sagno, C., Tounkara, E.O., 2003. The Republic of Guinea. In: Kormos, R., Boesch, C., Bakarr, M.I., Butynski, T.M. (Eds.), Status Survey and Conservation Action Plan West
African Chimpanzees. IUCN/SSC Primate Specialist Group, IUCN, Gland, Switzerland and Cambridge.

Kortlandt, A., 1986. The use of stone tools by wild-living chimpanzees and earliest hominids. J. Hum. Evol. 15, 77-132.

Kortlandt, A., Holzhaus, E., 1987. New data on the use of stone tools by chimpanzees in Guinea and Liberia. Primates 28, 473-496.

Lemonnier, P., 1983. L'etude des systèmes techniques: Une urgence en technologie culturelle. Techniques et Culture 1, 11-34.

Leakey, M.D., 1971. Olduvai Gorge. Vol. 3, Excavations in Beds I and II, 1960-1963. Cambridge University Press, Cambridge.

Leroi-Gourhan, A., 1964. Le Geste et la Parole I: Technique et Language. Albin Michal, Paris.

Leroi-Gourhan, A., Brézillon, M., 1972. Fouilles de la Section 36 de Pincevent, Essai d'Analyse Ethnographique d'un Habitat Magdalénien. VII Supplément à Gallia Préhistoire. Éditions CNRS, Paris.

Lucas, G., 2000. Les industries lithiques du Flageolet I (Dordogne): approche économique, technologique, fonctionelle et analyse spatiale. Ph.D Dissertation, L'Université Bordeaux I.

Marchant, L.F., McGrew, W.C., 2005. Percussive technology: Chimpanzee baobab smashing and the evolutionary modelling of hominin knapping. In: Roux, V., Bril, B. (Eds.), Stone Knapping: The Necessary Conditions for a Uniquely Hominin Behaviour. McDonald Institute for Archaeological Research, Cambridge, pp. 341-350.

Matsuzawa, T., 1994. Field experiments on the use of stone tools by chimpanzees in the wild. In: Wrangham, R.W., McGrew, W.C., de Waal, F.B.M., Heltne, P.G. (Eds.), Chimpanzee Cultures. Harvard University Press, Cambridge, pp. 351-370.

Matsuzawa, T., 1996. Chimpanzee intelligence in nature and in captivity: Isomorphism of symbol use and tool use. In: McGrew, W.C., Marchant, L.F., Nishida, T. (Eds.), Great Ape Societies. Cambridge University Press, Cambridge, pp. 196-209.

Matsuzawa, T., 1999. Communication and tool use in chimpanzees: Cultural and social contexts. In: Hauser, M., Konishi, M. (Eds.), The Design of Animal Communication. MIT Press, Cambridge, pp. 645-671.

Matsuzawa, T., Yamakoshi, G., 1996. Comparison of chimpanzee material culture between Bossou and Nimba, West Africa. In: Russon, A.E., Bard, K.A., Parker, S. (Eds.), Reaching into Thought: The Mind of the Great Apes. Cambridge University Press, Cambridge, pp. 211-232.

Matsuzawa, T., Takemoto, H., Hayakawa, S., Shimada, M., 1999. Diecké Forest in Guinea. Pan Africa News 6, 10-11.

Matsuzawa, T., Biro, D., Humle, T., Inoue-Nakamura, N., Tonooka, R., Yamakoshi, G., 2001. Emergence of culture in wild chimpanzees: Education by master-apprenticeship. In: Matsuzawa, T. (Ed.), Primate Origins of Human Cognition and Behavior. Springer-Verlag, Tokyo, pp. $557-574$.

Mauss, M., 1967. Manuel d`Etnographie. Éditions Payot, Paris.

McGrew, W.C., 1992. Chimpanzee Material Culture-Implications for Human Evolution. Cambridge University Press, Cambridge.

McGrew, W.C., 2004. The Cultured Chimpanzee: Reflections on Cultural Primatology. Cambridge University Press, Cambridge.

Mercader, J., Panger, M., Boesh, C., 2002. Excavation of a chimpanzee stone tool site in the African rainforest. Science 296, 1452-1455.

Mercader, J., Barton, H., Gillespie, J., Harris, J., Kuhn, S., Tyler, R., Boesch, C., 2007. 4,300-year-old chimpanzee sites and the origins of percussive stone technology. Proc. Natl. Acad. Sci. U.S.A. 104, $1-7$.

Morgan, B., Abwe, E., 2006. Chimpanzees use stone hammers in Cameroon. Curr. Biol. 16, 632-633.

Nishida, T., 1987. Local traditions and cultural transmission. In: Smuts, B., Cheney, D., Seyfarth, R., Wrangham, R., Struhsaker, T. (Eds.), Primate Societies. The University of Chicago Press, Chicago, pp. 462-474.

Ohashi, G., 2006. Behavioural repertoire of tool use in the wild chimpanzees at Bossou. In: Matsuzawa, T., Tomonaga, M., Tanaka, M. (Eds.), Cognitive Development in Chimpanzees. Springer, Tokyo, pp. 439-451.

Oswalt, W.H., 1976. An Anthropological Analysis of Food-Getting Technology. John Wiley, New York.

Pelegrin, J., Karlin, C., Bodu, P., 1988. Chaînes opératoires: Un outil pour le préhistorien. In: Tixier, J. (Ed.), Technologie Préhistorique. C.N.R.S., Paris. 
Perlès, C., 1992. In search of lithic strategies a cognitive approach to prehistoric chipped stone assemblages. In: Gardin, J., Peebles, C.S. (Eds.), Presentations in Archaeology. Indiana University Press, Bloomington, pp. 223-247.

Sakura, O., Matsuzawa, T., 1991. Flexibility of wild chimpanzee nut-cracking behavior using stone hammers and anvils: an experimental analysis. Ethology 87, 237-248.

Sellet, F., 1993. Chaîne opératoire: the concept and its applications. Lithic Technol. 18, 106-112.

Semaw, S., Renne, P., Harris, J.W.K., Feibel, C.S., Bernor, R.L., Fesseha, N., Mowbray, K., 1997. 2.5-million-year-old stone tools from Gona, Ethiopia. Nature 385, 333-336.

Semaw, S., Rogers, M.J., Quade, J., Renne, P.R., Butler, R.F., DominguezRodrigo, M., Stout, D., Hart, W.S., Pickering, T., Simpson, S.W., 2003. 2.6-million-year-old stone tools and associated bones from OGS-6 and OGS-7, Gona, Afar, Ethiopia. J. Hum. Evol. 45, 169-177.

Semenov, S.A., 1981. Tecnología Prehistórica: Estudio de las Herramientas y Objectos Antiguos Através de las Huellas de Uso. Akal Universitária, Madrid.

Sept, J.M., 1992. Was there no place like home? A new perspective on early hominid archeological sites from the mapping of chimpanzees nests. Curr. Anthropol. 33, 187-207.

Schick, K.D., Toth, N., Garufi, G., Savage-Rumbaugh, E.S., Rumbaugh, D., Sevcik, R., 1999. Continuing investigations into the stone tool-making and tool-using capabilities of a bonobo (Pan paniscus). J. Archaeol. Sci. 26, 821-832.

Stokes, E.J., Byrne, R.W., 2001. Cognitive capacities for behavioural flexibility in wild chimpanzees (Pan troglodytes): the effect of snare injury on complex manual food processing. Anim. Cog. 4, 11-28.
Sugiyama, Y., 1981. Observation on the populations dynamics and behaviour of wild chimpanzees at Bossou, Guinea, 1979-1980. Primates $22,435-444$.

Sugiyama, Y., 1994. Tool-use by wild chimpanzees. Nature 367, 327.

Sugiyama, Y., 1997. Social tradition and the use of tool composites by wild chimpanzees. Evol. Anthropol. 6, 23-27.

Sugiyama, Y., Koman, J., 1979. Tool using and making behaviour in wild chimpanzees at Bossou, Guinea. Primates 20, 323-339.

Tixier, J., Inizan, M.-L., Roche, H., 1980. Préhistoire de la Pierre Taillée, Terminologie et Technologie. Éditions du Cercle de Recherches et d'Études Préhistoriques, Paris.

Toth, N., 1985. The Oldowan reassessed: a closer look at early stone artifacts. J. Archaeol. Sci. 12, 101-120.

Toth, N., Schick, K., 1993. Early stone industries and inferences regarding language and cognition. In: Gibson, K.R., Ingold, T. (Eds.), Tools, Language and Cognition in Human Evolution. Cambridge University Press, Cambridge, pp. 346-362.

Whiten, A., Goodall, J., McGrew, W.C., Nishida, T., Reynolds, V., Sugiyama, Y., Tutin, C., Wrangham, R., Boesch, C., 1999. Cultures in chimpanzees. Nature 399, 682-685.

Whiten, A., Boesch, C., 2001. The cultures of chimpanzees. Sci. Am. 284, 60-67.

Whiten, A., Spiteri, A., Horner, V., Bonnie, K.E., Lambeth, S.P., Schapiro, S.J., de Waal, F.B.M., 2007. Transmission of multiple traditions within and between chimpanzee groups. Curr. Biol. 17, 1038-1043.

Whitesides, G.H., 1985. Nut-cracking by wild chimpanzees in Sierra Leone, West Africa. Primates 26, 91-94.

Wynn, T., McGrew, W.C., 1989. An ape's view of the Oldowan. Man 24, 383-398. 